\title{
ENSAIO TERAPÊUTICO NA INFECÇÃO POR GIARDIA MURIS EM CAMUNDONGO COM METRONIDAZOLE, TINIDAZOLE, SECNIDAZOLE E FURAZOLIDONE
}

\author{
Claudia Cristina Pedigone Cruz, Lilian Ferrari e Roberto Sogayar
}

\begin{abstract}
Foi testado in vivo a sensibilidade de Giardia muris a quatro drogas comumente usadas no tratamento da giardiase bumana. Foram utilizados 7 grupos de animais, com 12 camundongos cada, sendo que o grupo controle recebeu apenas solução salina $0,15 \mathrm{M}(0,5 \mathrm{ml} /$ animal). Os demais grupos receberam em dose única: metronidazole e furazolidone $(500 \mathrm{mg} / \mathrm{kg})$, tinidazole e secnidazole (200mg/kg). A eficácia das drogas foi avaliada através da contagem de cistos nas fezes e pela ausência de trofozoítos no intestino. O metronidazole foi a droga mais eficaz. Os cortes histológicos mostraram diferenças entre o padrão da mucosa intestinal de animais normais e parasitados. No entanto, não se observou diferença entre o padrão de mucosa de animais infectados tratados e não tratados, o que sugere que estas alterações podem ser causadas pelo parasito e não pelas drogas.

Palavras-chaves: Tratamento. Giardia muris. Metronidazole. Tinidazole. Secnidazole. Furazolidone.
\end{abstract}

A Giardia muris é um parasito muito comum de animais em laboratório e tem sido muito utilizado como modelo no camundongo, para estudos de giardíase animal e humana19 relacionados principalmente com a imunologia dessa parasitose 31213.

Entretanto, existem poucos trabalhos que enfoquem de modo sistemático e comparativo a eficiência de drogas para o tratamento de Giardia de animais principalmente os relacionados com a giardíase murina. Em camundongos, testes terapêuticos com drogas utilizadas no tratamento de giardíase humana também são bastante escassos, principalmente os relacionados com os derivados do 5-nitroimidazole. Alguns autores obtiveram 100\% de cura para G. muris com o metronidazole16. Essa mesma droga e o secnidazole, nas dosagens respectivas de $150 \mathrm{mg} / \mathrm{kg}$ e $500 \mathrm{mg} / \mathrm{kg}$, mostraram eficácia de $100 \%$ quando ministradas por 2 dias consecutivos em camundondogos naturalmente infectados 2 . Drogas usadas conforme as dosagens prescritas na bula, como o metronidazole (1 e $2 \mathrm{mg} /$ camundongo/dia/5 dias), furazolidone

Departamento de Parasitologia, Instituto de Biociências, Universidade Estadual Paulista (UNESP), Campus de Botucatu, Botucatu, SP

Endereço para correspondência: Prof. Roberto Sogayar. Dept $^{\circ}$ de Parasitologia/IB/UNESP, Campus de Botucatu, 18618-000, Rubião Júnior, Botucatu, SP. Fax: (014) 821-3744 Recebido para publicação em 15/12/95.
$(5 \mathrm{mg} / \mathrm{kg} / 7$ dias) e tinidazole $(30 \mathrm{mg} / \mathrm{kg} /$ dose única) mostraram taxas de cura, em camundongos naturalmente infectados, de $100 \%, 12 \%$ e $22 \%$ respectivamente (CC Pedigone e cols: dados não publicados). O tratamento da G. muris com dimetridazole $0,1 \%$ na água de beber dos animais, por 14 dias, não foi bem sucedido20. Tendo em vista a discrepância dos resultados relacionados às drogas mencionadas e a ausência de dados sobre a ação do tinidazole e furazolidone sobre a $G$. muris, realizou-se este estudo comparativo a fim de verificar a eficácia de 3 compostos derivados do 5-nitroimidazole (metronidazole, tinidazole e secnidazole) e um derivado nitrofurano (furazolidone) sobre G. muris de camundongos naturalmente infectados. Concomitantemente, foi feito um estudo histológico da mucosa intestinal dos animais, antes e após tratamento, visando a observação e comparação das prováveis alterações causadas pelo parasita e/ou pelas drogas.

\section{MATERIAL E MÉTODOS}

Animais. Foram utilizados 72 camundongos machos, albinos, Swiss, pesando $20 \mathrm{~g}$, naturalmente infectados por Giardia muris, provenientes do Biotério Central da UNESP, Botucatu. Também foram utilizados 12 camundongos "SPF", cedidos pelo Centro Multi-Institucional de Bioterismo da 
Cruz CCP, Ferrari L, Sogayar R. Ensaio terapêutico na infecção por Giardia muris em camundongos com metronidazole, tinidazole, secnidazole e furazolidone. Revista da Sociedade Brasileira de Medicina Tropical 30:223-228, mai-jun, 1997.

UNICAMP/CEMIB, que serviram de grupo controle na análise histológica. Todos os animais foram mantidos no Biotério do Dept ${ }^{\mathrm{o}}$ de Parasitologia em caixas plásticas de fundo telado, para evitar o contato com as fezes e possíveis reinfecções durante o experimento.

Grupos experimentais. Os grupos experimentais, as drogas e os esquemas terapêuticos utilizados são apresentados na Tabela 1. A dosagem das drogas foi estabelecida de acordo com o peso dos animais e em dose única.

Diagnóstico e intensidade da infecção. Foram realizados três exames de fezes pelo método de Faust e cols 25 , por animal, em dias alternados antes do início do tratamento. Os animais foram acondicionados em gaiolas individuais durante duas horas para coleta de fezes. Após, foi feita a pesagem das fezes e a contagem do número de cistos em câmara de Neubauer19.

Controle de cura. Após o término do tratamento foram realizados exames de fezes individuais dos animais por três dias consecutivos, utilizando o mesmo procedimento já descrito no item anterior. Em seguida, todos os animais foram necropsiados 19 para verificar a presença de trofozoítos na mucosa intestinal. Adotou-se como critério de cura a ausência de trofozoítos no intestino delgado. Foram colhidos dois fragmentos da porção média do intestino delgado (longitudinal e transversal) de todos os camundongos tratados e controles. A seguir foram feitos cortes histológicos de $6 \mu$ de espessura e coloração com hematoxilinaeosina (HE).

Análise estatística. Para contagem do número de cistos/g de fezes utilizou-se o teste não paramétrico de Kruskal-Wallis21; os dados da necropsia foram analisados pelo teste de comparações múltiplas de Goodman dentro e entre populações binomiais9 10; para a comparação dos valores médios obtidos nas pesagens das fezes utilizou-se o teste " $\mathrm{t}$ " de Student para amostras dependentes.

Tabela 1 - Grupos experimentais utilizados para estudar o efeito de diferentes drogas, administradas por "gavage" em dose única, sobre G. muris em camundongos naturalmente infectados.

\begin{tabular}{lllll}
\hline Grupo & No animais & \multicolumn{1}{c}{ Tratamento } & $\begin{array}{c}\text { Dosagem } \\
\text { Esquema tratamento } \\
\text { (dose única) }\end{array}$ \\
\hline Placebo & 12 & solução salina $0,15 \mathrm{M}$ & $0,5 \mathrm{ml}$ & $0,5 \mathrm{ml}$ \\
Metronidazole & 12 & metronidazole (Flagyl) & $500 \mathrm{mg} / \mathrm{kg}$ & $10 \mathrm{mg} / \mathrm{cdgo} / 0,5 \mathrm{ml}$ \\
Furazolidone & 12 & furazolidone (Giarlan) & $500 \mathrm{mg} / \mathrm{kg}$ & $10 \mathrm{mg} / \mathrm{cdgo} / 1,0 \mathrm{ml}$ \\
Tinidazole & 12 & tinidazole (Amplium) & $200 \mathrm{mg} / \mathrm{kg}$ & $0,4 \mathrm{mg} / \mathrm{cdgo} / 0,5 \mathrm{ml}$ \\
Secnidazole & 12 & secnidazole (Secnidal) & $200 \mathrm{mg} / \mathrm{kg}$ & $0,4 \mathrm{mg} / \mathrm{cdgo} / 0,5 \mathrm{ml}$ \\
Infectado & 12 & controle histológico infectado & - & - \\
Normal & 12 & controle histológico normal (SPF) & - & - \\
\hline
\end{tabular}

\section{RESULTADOS}

Analisando a eficácia do tratamento através da contagem de cistos por grama de fezes (Tabela 2) observou-se que apenas o grupo que foi tratado com furazolidone diferiu estatisticamente do grupo controle, no segundo dia de exames após o tratamento. Aos 16 dias antes do início do tratamento houve diferença significativa entre os animais dos grupos placebo $(\mathrm{P}) \mathrm{x}$ secnidazole $(\mathrm{S})$, furazolidone $(\mathrm{F})$ $\mathrm{x}$ metronidazole $(\mathrm{M})$, furazolidone $\mathrm{x}$ tinidazole (T) e furazolidone $x$ secnidazole $(p<0,01)$, quanto ao número de cistos eliminados.

Em relação à ação das drogas sobre os trofozoítos (Tabela 3), foi mostrada uma diferença significativa na porcentagem de cura entre o metronidazole $(58,3 \%)$ e o furazolidone $(50,0 \%)$ em relação ao grupo controle; já com o tinidazole $(16,0 \%)$ e o secnidazole $(40,0 \%)$ não foi possível constatar estas diferenças.

A análise dos dados referentes à $1^{\underline{a}}$ e $2^{\underline{a}}$ pesagens de fezes antes do tratamento mostrou que as médias da primeira diferiram estatisticamente das médias da segunda, para o grupo controle e os tratados com furazolidone, metronidazole e tinidazole. Já para o secnidazole, não houve diferença significante (Tabela 4). As demais pesagens não apresentaram diferença em relação à segunda.

Quanto à histologia, o exame da porção média da mucosa intestinal dos camundongos dos 
Cruz CCP, Ferrari L, Sogayar R. Ensaio terapêtutico na infecção por Giardia muris em camundongos com metronidazole, tinidazole, secnidazole e furazolidone. Revista da Sociedade Brasileira de Medicina Tropical 30:223-228, mai-jun, 1997.

sete grupos examinados demonstrou haver diferença entre o padrão de mucosa apresentado pelo grupo não infectado e não tratado $(\mathrm{N})$ que era "SPF", com os demais grupos infectados tratados ou não. O grupo controle "SPF" apresentou um padrão normal de mucosa e os demais grupos apresentaram a mucosa alterada com áreas de inflamação, aumento das células das criptas nas glândulas de Lieberkühn, discreto aumento das vilosidades intestinais e presença de trofozoítos no ápice, base e entre as vilosidades.

Tabela 2 - Médias do número de cistos de G. muris por grama de fezes, eliminados antes e após tratamento e resultados do teste de KruskalWallis.

\begin{tabular}{|c|c|c|c|c|c|c|}
\hline \multirow{2}{*}{$\begin{array}{c}\text { Data de } \\
\text { avaliação } \\
\text { (dias) }\end{array}$} & \multicolumn{5}{|c|}{ Grupos } & \multirow{2}{*}{$\begin{array}{c}\text { Resultado do } \\
\text { teste } \\
\text { estatístico }\end{array}$} \\
\hline & $\mathrm{P}$ & M & $\mathrm{F}$ & $\mathrm{T}$ & $S$ & \\
\hline 16 antes & $34,17 \mathrm{bc}^{*}$ & $30,92 \mathrm{ab}$ & $42,42 \mathrm{c}$ & $23,50 \mathrm{ab}$ & $13,90 a$ & $18,07(\mathrm{p}<0,01)$ \\
\hline 6 antes & $28,66 a$ & $25,25 \mathrm{a}$ & $39,41 \mathrm{a}$ & $29,75 a$ & $23,40 a$ & $6,23(\mathrm{p}>0,05)$ \\
\hline 1 após & $36,20 \mathrm{a}$ & $29,66 \mathrm{a}$ & $25,20 \mathrm{a}$ & $28,70 \mathrm{a}$ & $27,35 \mathrm{a}$ & $2,73(\mathrm{p}>0,05)$ \\
\hline 2 após & $42,33 b$ & $32,91 \mathrm{ab}$ & $17,83 \mathrm{a}$ & $28,41 \mathrm{ab}$ & $25,30 \mathrm{ab}$ & $13,81(\mathrm{p}<0,01)$ \\
\hline 3 após & $31,62 \mathrm{a}$ & $23,50 \mathrm{a}$ & $23,91 \mathrm{a}$ & $31,37 \mathrm{a}$ & $38,60 \mathrm{a}$ & $6,06(\mathrm{p}>0,05)$ \\
\hline
\end{tabular}

* médias seguidas de uma mesma letra minúscula não diferem entre si.

Tabela 3 - Proporção entre $n^{\circ}$ de animais positivos ou negativos para trofozoítos de $\mathrm{G}$. muris pelo $n^{\circ}$ total de animais, nos cinco grupos experimentais apos tratamento e o resultado do teste de Goodman e as respectivas taxas de cura.

\begin{tabular}{|c|c|c|c|c|}
\hline \multirow[b]{2}{*}{ Grupos } & \multicolumn{2}{|c|}{ Necropsia (trofozoítos) } & \multirow[b]{2}{*}{$\%$ cura } & \multirow{2}{*}{$\begin{array}{c}\text { Animais negativos } \\
\text { sobre total }\end{array}$} \\
\hline & presente & ausente & & \\
\hline \multirow[t]{2}{*}{ placebo } & $1,000 b^{*}$ & $0,000 \mathrm{a}$ & 0,0 & $0 / 11$ \\
\hline & $\mathrm{B}^{* * *}$ & $\mathrm{~A}$ & & \\
\hline \multirow[t]{2}{*}{ metronidazole } & $0,417 \mathrm{a}$ & $0,583 b$ & 58,3 & $7 / 12$ \\
\hline & A & A & & \\
\hline \multirow[t]{2}{*}{ furazolidone } & $0,500 \mathrm{a}$ & $0,500 \mathrm{~b}$ & 50,0 & $6 / 12$ \\
\hline & A & A & & \\
\hline \multirow[t]{2}{*}{ tinidazole } & $0,833 \mathrm{ab}$ & $0,167 \mathrm{ab}$ & 16,0 & $2 / 12$ \\
\hline & $\mathrm{B}$ & A & & \\
\hline \multirow[t]{2}{*}{ secnidazole } & $0,600 \mathrm{ab}$ & $0,400 \mathrm{ab}$ & 40,0 & $4 / 10$ \\
\hline & A & A & & \\
\hline
\end{tabular}

* proporções seguidas de uma mesma letra minúscula nas linhas, não diferem entre si.

${ }_{* *}^{*}$ proporções seguidas de uma mesma letra maiúscula nas colunas, não diferem entre si.

Tabela 4 - Médias obtidas na primeira e segunda pesagem das fezes antes do tratamento e resultado do teste estatístico (" $t$ " de Student).

\begin{tabular}{lccc}
\hline \multicolumn{1}{c}{ Droga } & \multicolumn{2}{c}{ Médias } & $\begin{array}{c}\text { Teste" } \mathrm{t} \text { " de Student } \\
\text { ("p value") }\end{array}$ \\
\cline { 2 - 4 } placebo & $1^{\mathrm{a}}$ pesagem & 1,111 & $\mathrm{t}=5,06(\mathrm{p}<0,001)$ \\
metronidazole & 0,562 & 0,981 & $\mathrm{t}=3,90(\mathrm{p}<0,005)$ \\
furazolidone & 0,548 & 0,814 & $\mathrm{t}=3,41(\mathrm{p}<0,005)$ \\
tinidazole & 0,447 & 1,079 & $\mathrm{t}=8,23(\mathrm{p}<0,001)$ \\
secnidazole & 0,497 & 0,533 & $\mathrm{t}=0,20(\mathrm{p}<0,05)$ \\
\hline
\end{tabular}

\section{DISCUSSÃO}

É de fundamental importância que os animais de bioexperimentação, utilizados como modelos para estudo de diversas patologias humanas, estejam livres de infecções 11. Dessa forma, a escolha de drogas eficazes na erradicação da G. muris, parasita comum em roedores, é um fator decisivo para o bom desenvolvimento das pesquisas. Além disso, este parasito no camundongo tem sido muito utilizado como modelo para estudo de giardíase humana. Por estas razões, comparou-se a ação de diferentes drogas no tratamento da giardíase murina. A possibilidade de reinfecção foi descartada, devido ao uso de caixas plásticas de fundo telado, que impediam o contato dos animais com as fezes.

Neste trabalho, adotou-se a estratégia da administração em dose única de três derivados de 5-nitroimidazole ( $M, T, S)$ e um nitrofurano (F), buscando viabilizar o tratamento de grandes lotes de animais com um mínimo de manuseio 
Cruz CCP, Ferrari L, Sogayar R. Ensaio terapêutico na infecção por Giardia muris em camundongos com metronidazole, tinidazole, secnidazole e furazolidone. Revista da Sociedade Brasileira de Medicina Tropical 30:223-228, mai-jun, 1997.

do plantel, obtendo porcentagens de cura que variaram de $16 \%(\mathrm{~T})$ a $58,3 \%(\mathrm{M})$ (Tabela 3).

Por se tratar de uma infecção natural, onde o inóculo é desconhecido e não padronizado, pode-se encontrar uma variabilidade muito grande na eliminação de cistos do parasita pelos camundongos, que no presente estudo foi de zero a 1816 cistos/g fezes. Isto poderia explicar a diferença significativa encontrada entre os grupos antes do início do tratamento (Tabela 2), quando os animais também apresentaram aumento do peso das fezes na $2^{\mathrm{a}}$ pesagem. Esta diferença detectada logo no ínicio do experimento provavelmente deve-se ao aparecimento de episódios de diarréia relacionados com o estresse sofrido pelo animais durante as sucessivas coletas de fezes.

Analisando a eficácia do tratamento através da contagem do número de cistos/g fezes (Tabela 2), verificou-se que apenas o furazolidone diferiu estatisticamente do grupo placebo, no segundo dia de exames de fezes após o tratamento. Com relação aos resultados obtidos na necropsia, o metronidazole apresentou uma porcentagem de cura de $58,3 \%$ e o furazolidone $50 \%$ (Tabela 3), No grupo tratado com metronidazole, apesar de sete animais se apresentarem negativos para trofozoítos na necropsia, todos continuarem eliminando cistos nas fezes (Tabela 2). Sabe-se que os cistos de G. muris não são afetados por esta droga e a sua eliminação pode ocorrer durante alguns dias após o tratamento18. São os chamados cistos residuais, que podem explicar a presença de cistos nos exames de fezes mesmo no terceiro dia após o tratamento. No grupo tratado com furazolidone apenas um animal foi negativo para cistos e trofozoítos concomitantemente. Tinidazole e secnidazole apresentaram porcentagens de cura menores que o metronidazole e o furazolidone, de 16 e $40 \%$ respectivamente, em relação à ausência de trofozoítos na mucosa intestinal dos animais. Isto pode ser devido à sensibilidade da G. muris a estas drogas ou às dosagens aqui testadas15. Os animais tratados com estas drogas também continuaram eliminando cistos após o tratamento, com uma discreta redução (Tabela 2). Confirmando a eficácia do metronidazole e do furazolidone, verificou-se que existe diferença entre estes dois grupos e o placebo, comparandoos em relação à presença ou ausência de trofozoítos. Já com tinidazole e secnidazole, não foi possível constatar esta diferença (Tabela 3).
As alterações encontradas nos cortes histológicos do intestino dos animais parasitados tratados ou não já foram descritas por vários autores1 45678141719222324 26. Não houve, entretanto, diferença entre as alterações encontradas nos grupos infectados tratados e não tratados, mostrando que estas podem ser decorrentes do parasitismo e não da ação das drogas sobre a mucosa intestinal dos animais.

Os resultados apresentados neste trabalho mostram que o critério mais seguro para avaliação da eficiência de uma droga é a ausência de trofozoítos na mucosa, já que as drogas não agem sobre cistos de Giardia, pois mesmo em animais sem trofozoítos no intestino delgado ocorre eliminação de cistos residuais da infecção. Portanto, quando se usar o exame de fezes para detecção de cistos como controle de cura é necessário fazer, além do seguimento dos animais por um tempo mais prolongado, a prevenção para que não ocorra reinfecção. Estes dados sugerem a vantagem de se fazer a necropsia em uma amostra do plantel tratado, tornando o controle de cura mais rápido e seguro. Se nos ensaios terapêuticos existem problemas sérios em relação à confiabilidade na ingestão da droga e quanto às reinfecções, neste experimento esses problemas foram descartados. Se a eficácia das drogas em camundongos foi mais baixa que as relatadas para o homem, ela pode estar relacionada com a sensibilidade de G. muris às drogas usadas em giardíase humana, nas dosagens aqui testadas.

A estratégia de tratamento em dose única, proposta neste trabalho, mostrou que a $G$. muris foi sensível ao metronidazole e ao furazolidone. Sendo assim, novos ensaios poderiam estabelecer dosagens eficazes na erradicação deste parasita, abrindo perspectivas de se ter plantéis com animais sadios, garantindo resultados confiáveis nas pesquisas.

\section{SUMMARY}

A comparative study about the effectiveness of metronidazole, tinidazole, secnidazole and furazolidone was performed on Giardia muris from mice naturally infected. Groups of 12 animals each was constituted: the control treated with saline; one treated with metronidazole; one treated with furazolidone; one treated with tinidazole; one treated with secnidazole; histological normal control; histological infected. Samples of three stools were examined before and after treatment with 
Cruz CCP, Ferrari L, Sogayar R. Ensaio terapêutico na infecção por Giardia muris em camundongos com metronidazole, tinidazole, secnidazole e furazolidone. Revista da Sociedade Brasileira de Medicina Tropical 30:223-228, mai-jun, 1997.

quantification of cysts. Animals were cured when the trophozoites was not seen in the small bowel. The curative activity of drugs was $58.3 \%$ for metronidazole, $50 \%$ for furazolidone, $40 \%$ for secnidazole and $16 \%$ for tinidazole. It was also showed that there was a different pattern of the intestinal mucosa from the control and infected groups, treated or not, suggesting that the alterations encountered in the mucosa of infected animals were due to the parasitism either the action of the drugs.

Key-words: Treatment. Giardia muris. Metronidazole. Tinidazole. Secnidazole. Furazolidone.

\section{AGRADECIMENTOS}

Os autores agradecem à Profa. Maria Inês T.L. Sogayar pelas sugestões e revisão do texto, à Prof ${ }^{\mathrm{a}}$ Edméia Dias pelo auxílio na parte histológica e ao Prof. Carlos Roberto Padovani pela análise estatística.

\section{REFERÊNCIAS BIBLIOGRÁFICAS}

1. Ament ME, Rubin CE. Relation of giardiasis to abnormal intestinal structure and function in gastrointestinal immunodeficiency syndromes. Gastroenterology 62:216-226, 1972.

2. Benazet F, Guillaume L. Activité antimicrobienne et tricomonacide du secnidazole and laboratoire. Bulletin de Societé Pathologie Exotique 69:309319, 1976.

3. Brett S, Cox FEG. Immunological aspects of Giardia muris and Spironucleus muris infections in inbred and outbred strains of laboratoy mice: a comparative study. Parasitology 85:85-99, 1982.

4. Buret A, Gall DG, Nation PN, Olson ME. Intestinal protozoa and epithelial cell kinetics, structure and function. Parasitology Today 6:375-380, 1990a.

5. Buret A, Gall DG, Olson ME. Effects of murine giardiasis on growth, intestinal morfology and dissacaridase activity. Journal Parasitology 76:403409, 1990b.

6. Buret A, Gall DG, Olson ME. Growth activities of enzymes in the small intestine, and ultrastructure of microvillous border in gerbils infected with Giardia duodenalis. Parasitology Research 77:109114, 1991.

7. Chawala LS, Sehgal AK, Broor SL, Verma RS, Chhuttani PN. Tryptic activity in the duodenal aspirate following a standard test meal in giardiasis. Scandinavian Journal of Gastroenterology 10:445-447, 1975.

8. Erlandsen SL, Chase DG. Morphological alterations in the microvillous border of villous epithelial cells produced by intestinal micoorganisms. The American Journal of Clinical Nutrition 27:1277-1286,1974.

9. Goodman LA. Simultaneous confidence intervals for contrasts among multinomial populations. Annals of Mathematical Statistics 35:716-725, 1964.

10. Goodman LA. On simultaneous confidence intervals for multinomial proportions. Technometrics 7:247-254, 1965.

11. Grant DR, Woo PTK. Comparative studies of Giardia spp in small mammals in Southern Ontário. II. Host specificity and infectivity of stored cysts. Cannadian Journal of Zoology 56:1360-1366, 1977.

12. Heyworth MF. Intestinal $\operatorname{IgA}$ responses to Giardia muris in mice depleted of helper $\mathrm{T}$ lymphocytes and in immunocompetent mice. Journal Parasitology, 75:246-253, 1989.

13. Hill DR. Lymphocyte proliferation in Peyer's patches of Giardia muris infected mice. Infection and Immunity 58:2683-2685, 1990.

14. Lerman SJ, Walker RA. Treatment of giardiasis. Parasitology 21:409-414, 1982.

15. Majewska AC, Kasprzak W, Dejoncheere JF, Kaczemarek E. Heterogeneity in the sensitivity of stock and clones of Giardia to metronidazole and ornidazole. Transactions of the Royal Society of Tropical Medicine Hygiene 85: 67-69, 1991.

16. Mandoul R, Darejos R, Millan J. Destruction des protozoaires intestinaux de la souris par un derivé nutré de 1'imidazole. Bulletin de Société Pathologie Exotique 54:12-16, 1961.

17. Owen RL, Nemanic PC, Stevens DP. Ultrastructural observations on giardiasis in a murine model. Gastroenterology, 76: 757-769, 1979.

18. Paget TA, Jarroll EL, Manning P, Lindmark D, Lloyd D. Respiration in the cysts and trophozoite of Giardia muris. Journal of General Microbiology 135:145-154, 1989

19. Roberts-Thomson JC, Stevens DP, Mahmoud AAF, Warren KS. Giardiasis in the mouse: an animal model. Gastroenterology 71:57-61, 1976.

20. Sbesteny A. Pathogenicity of intestinal flagellates in mice. Laboratory Animals 3:71-77, 1969.

21. Siegel S. Estatística não paramétrica para ciências do comportamento. Mc Graw Hill do Brasil, 1981.

22. Snider DP, Skea D, Underdown BJ. Chronic giardiasis in B-cell deficiency mice expressing de 
Cruz CCP, Ferrari L, Sogayar R. Ensaio terapêutico na infecção por Giardia muris em camundongos com metronidazole, tinidazole, secnidazole e furazolidone. Revista da Sociedade Brasileira de Medicina Tropical 30:223-228, mai-jun, 1997.

xid gene. Infection and Immunity 56:2838-2842, 1988.

23. Tandom BL, Puri BK, Gandhi PC, Tewari SG. Mucosal surface injury of jejunal mucosa in patients with giardiasis - an electron microscope study. Indian Journal of Medical Research 62:1838-1842, 1974.

24. Thompson RCA, Reynoldson JA. Giardia and giardiasis. Advances in Parasitology 32:71-160, 1993.
25. Vallada EP. Manual de exame de fezes. Coprologia e parasitologia. Atheneu 201 p, 1988.

26. Wolfe MS. Clinical symptoms and diagnosis by traditional methods. In: "Giardiasis" (E. A. Meyer, ed.). Elsevier,Amsterdan, p. 175-185, 1990. 